\author{
Acta Scientifica Naturalis \\ Former Annual of Konstantin Preslavsky University - Chemistry, Physics, Biology, Geography \\ Journal homepage: http://www.shu.bg
}

Received: 30.10.2016

Accepted: 11.01.2017

\title{
Diagnosis of the socionic temperament of personality and creating a psychological portrait of the Western European SPA and wellness tourists in Bulgaria
}

\author{
Milena Stoyanova \\ "Konstantin Preslavsky" University of Shumen, \\ Faculty of Natural Sciences, Department of Tourism, \\ 115 Universitetska Str., 9712, Shumen, Bulgaria \\ e-mail: stoyanovamilena@abv.bg
}

\begin{abstract}
Human personality is a set of psychological characteristics that distinguishes it from others. However people can be classified as congenital personality types, interactions that are precisely defined. The aim of this article is to characterize the socionic temperament and psychological profile of the spa and wellness tourists in Bulgaria. The study is based on a survey of 460 tourists who visited Bulgarian spa centers in the summer and autumn of 2015.
\end{abstract}

Keywords: spa and wellness, western European tourists, socionic temperament, psychological profile

\section{Introduction}

Personality and its surrounding world are probably the most important system that interests humanity. All human life is an interaction with the world outside: with other people, groups, government structures, objects of the animate and inanimate nature, etc. If a person does not interact with the world outside, he did not exist for the world. Therefore one of the most important personal dimension is significance that someone acquires in lives of the others, of the community, and through that he realizes itself and achieves the meaning of his life.

Human personality is a set of psychological characteristics that distinguishes it from others. However people can be classified as congenital personality types, interactions that are precisely defined.

Perception is usually intergrated with activities related to exposition, attention and interpretation of outside stimuli. In addition, these activities depend on the stimulating qualities and the individual inner factors [2]. In tourism, the image of a certain destination in the mind of the individual (the perception of the destination) is usually realized on the base of stimulating processes which can be significantly influenced by individual psychological factors. Based on this assumption is the influence of the psychological motives and cultural values on perceiving the image of a tourist destination.

Socionics, which closely relates to social psychology, is a science that studies the exchange between the individual and the outside world which means how people perceive, process and emit information. It helps for understanding other people's abilities, what can be demanded from them and what can be expected. On this basis, it is possible to draw a full picture of human behaviour and reactions to others and to the individual themselves [1].

Researchers try to find the relation between the individual and their intention to follow one or another example of behavior through the theory of traits. But even though certain traits define the type of behavior the client has, it's hard to be used in the segmentation of the market because:

- People with similar personality traits should be similar in their demographic indexes too (age, income, place of living) which explains the need to be attracted by certain media.

\section{4}

Corresponding author: stoyanovamilena@abv.bg

DOI: 10.1515/asn-2017-0013 
- People with different personality traits can be attracted by one and the same indexes of the product. Many products and services go together because they often are chosen by the same people.

According to their psychological characteristics, the clients can be classified in a few types. This structure is totally natural and comes from the psychological content of the consumer behaviour. The style of consumer behaviour is defined by the temperament, the self-awareness and the self-actualization, the lifestyle and the communicativity of the clients. Different methods can be used for defining the target group and and its quantity determination for the reason that people's interest in the product or the service is not always the same, direct or immediate, it is often not obvious, logical (just as spontaneous purchases) or conscious.

Market behaviour does not always support the suggestion of the specialist regarding customs of consumer. That is why the determing of the target groups is preceded by collecting a lot of primary information by sociometric methods - tests and surveys. Thus are determined the participation of the individuals in buying and selling is defined (for example, real and potential buyers and non-buyers, the way of consumption and its types (for example, regular, temporary and random consumers, etc) [5]. They are used to study the process of information exchange between man and the outside world, ie how people perceive, process and emit information. They help to better understand the capabilities of others, what may be required of them and what can be expected. This enables framing of a comprehensive picture of human behavior and reactions to others and himself [1].

Human personality is a set of psychological characteristics that distinguishes it from others. However, people can be classified by innate personality types, interactions that are precisely defined. Psychologists have long started to pay attention to the significant individual differences in human behavior. There are some typical "models of behaviors": in the same situation, a person with certain psychological qualities always acts in the same way. Therefore, there is not only the structure of the individual, but also structure the relationship.

Some psychologists argue that the term "personality" may not be valid. Many studies have found that people do not manifest themselves as strong individuals because they do not necessarily act the same way in all situations and based on that people can be categorized. On an intuitive level, it is difficult to accept because usually others are observed in a limited number of situations, so they really look inconsistent. Many psychologists recognize that the fundamental characteristics of man are only one part of the puzzle, and situational factors often play a large role in determining behavior [4]. And since the base of the communication and tourism are individuals, it is imperative that by clarifying the psychology of personality, attention should be focused on individual internal mechanisms and on similarities between individuals.

Temperament is a configuration of obvious personality traits such as communication habits, courses of action and a collection of distinctive attitudes, values and talents. It also includes personal needs, contributions in the workplace and the role they play in society. To use the idea of temperament most effectively, it is important to understand that all four species are not simply arbitrary set of characteristics, but the result of the interaction of two basic dimensions of human behavior, communication and actions, words and deeds, or just what is said and what is done.

Therefore, some aspects of the personality continue to be included in marketing strategies. Spa and wellness tourism use these dimensions together with the election of human activities in leisure time, aesthetic tastes and other individual factors consumers to be classified in terms of lifestyle. In marketing, purchase of tourist product is a result of the impact of incentives for satisfying any need. As individual motivation is the driving force for human consumption, its research involves the study of factors that drive users to behave in a certain way, establishing the defining incentives, needs and desires and ways to their fullest satisfaction. So by studying the lifestyle of people, the consumption of product can be predicted and knowing the factors that stimulating lifestyle, consumer behavior can be redirected in respect of a particular product. And precisely via advertising is carried out its impact as a major marketing tool for influencing the consumer.

In motivation, personality manifests itself as a complete system that interacts with a more sophisticated system of natural and social reality. The systematic approach reveals the nature of these relationships, the whole complex of internal and external interactions of the individual [3]. So the interactions between the individual and its enviroment are included in the motivational process in which the whole human mind takes part. In such motivational relation, the most important for individual is the purpose of choosing an activity and the adequacy of the choice. The place and the social attitude are important for the choice of motif. Sometimes it is 
identified with the mental attitude which manages the reactions of the individual as an invisible actualization of our tendencies, views and needs.

\section{Objectives}

The aim of this study is specify the socionic temperament of the Western European spa and wellness tourists in Bulgaria and to create their psychological portraits based on the results. In order to do that, the tasks below should be solved:

- To specify the terms socionic temperament and psychological portrait;

- To implement adequate methods for diagnosing socionic temperament (Keirsey's test);

- To develop and implement a methodology for creating a psychological portrait of spa and wellness tourists based on their socionic temperament;

- To perform quantitative and qualitative analysis of the results.

The object of study is the personality of the tourists and the subject - their socionic temperament, and on its basis - the creation of their psychological portrait.

\section{Methodology}

D. Keirsey (1950) manages to seperate, describe in detail and use in practise the types of temperament and the psychological portraits [6]. Temperament is a complex of steady individual psychological characteristics which determine the dynamics of the psychological activity of the individual, which remain relatively constant through different motives, contents and goals of the activity. It's the most active individual characteristic of a person which can't be significantly changed in the process of the activity. Of all the components of the overall mental activity, it is most closely associated with the emotional sphere. Thus emotional excitability as a property of temperament expresses the rhythm of the flow of emotions in different temperaments.

According to him, the types of temperament are some kind of universal regulators that adjust the properties of the perceiver organism to the nature of the external impact. There are four specified types of temperapent each one of which is divided to four psychological portraits.

Different combination of the last three pairs of preferences reveals the types of temperament (it suggests realization of the qualities of the individual which give an unique originality of all the manifestations of the individual, of one's individuality).

By using the standardized Keirsey's test, it can follow the quality proportion in the same personality type in terms of the four functions and the relations:

- Extravertion-Introvertion (E - I);

- Sensation-Intuition $(\mathrm{S}-\mathrm{N})$;

- Thinking-Feeling $(\mathrm{T}-\mathrm{F})$;

- Judging-Perceiving $(\mathrm{J}-\mathrm{P})$.

Ten of these 70 claims relate to the scale of extraversion, introversion, and the rest (three groups of 20) reveal the contents of the other three rates. Scales of sincerity and authenticity in the poll are not affected. The allegations follow homogeneous groups of seven questions: the first refers to the factors of E-I, second and third - the factors S-N, fourth and fifth - factors T-F, sixth and seventh - factors J-P. Any statement has two options (designated as a) or b), one of which must be selected. Thus, indicate individual preferences for each one of the paired factors for each of the four pairs. At the end, the respondent receives the result whether it is extrovert or introvert, sensitive or intuitive, etc.

The test of 70 questions has been applied for research of the Western European spa and wellness tourists in relation with their consulting and choice of destination and product. The possible combinations of the pairs of factors make it possible for the type of temperament and the psychological portrait of an individual to be defined [6].

\section{Results}

From the obtained data with a standardized Kiersey's test, can be generalize these results about psychological profile and temperament of the surveyed spa and wellness tourists: 54\% of them are extroverts, 36\% introverts and $10 \%$ are ambiverts. In a friendly company they socialize with many people just as these who prefer to socialize in a close circle. Those are mainly people who are in touch with the most recent events 86

Corresponding author: stoyanovamilena@abv.bg

DOI: 10.1515/asn-2017-0013 
$(62.5 \%)$ and ones who hear news with some delay (37.5\%). New and unusual relationships with people stimulate and give energy to $80 \%$ of the interviewed and $20 \%$ get exhausted from that. $66.3 \%$ of the tourists see themselves as open and approachable for other people while $33.7 \%$ view themselves as reserved and distanced.

The second alternative pair determines psychological portraits "Sensation-Intuition". According to the results $70.0 \%$ of the respondents identified themselves as realistic people, and only 30.0 percent - as willing to theorize. Surveyed distinguish themselves as sensible (75.0\%) and people with a rich imagination (25.0\%). Only 7.5 percent of them like to do everyday things in the usual way, and the remaining $92.5 \%$ - in its own original way. Those are people who believe that facts are important to themselves $-81.3 \%$, and others who believe that the facts are a manifestation of general rules $-18.7 \%$. 56,3\% see their actions as ones of a practical person and $43,7 \%$ - as of an original one. The interviewed define themselves as more prone to find profit in their relationships with people $(33,7 \%)$ and more prone to understanding the thoughts and the feelings of others $(66,3 \%) .81,3 \%$ say that they are guided by the facts and the circumstances and only $18,7 \%$ are guided by the generally accepted understanding and principles. $60 \%$ trust their experience while $40 \%$ their gut feelings. $62,5 \%$ value their developped sense of reality and the other 37,5\% - their rich imagination. An important coclusion is that most of the Western European tourists who want to experience spa and wellness tourism in Bulgaria are sensintive type rather than intuitive one.

The third alternate pair examines the relation "Thinking-Feeling". $25 \%$ feel more influenced by laws and principles and $75 \%$ - by emotions and feellings. When assessing their actions, only $17.5 \%$ of the sample reported more requirements of the law than the circumstances, and the remaining $82.5 \%$ is the opposite - take into account the circumstances more than required by law. When they turn to the others $37.5 \%$ of the study group are inclined to comply with labeling and formalities while $62.5 \%$ prefer to exhibit their personal, individual qualities. $41.3 \%$ of them are unabashed and $48.7 \%$ - hot-tempered. $t$ is important to specify that in deciding these tourists rather be guided by their feelings and sensations $(81.3 \%)$ and less than accepted norms $(18.7 \%)$. Most of them seek to achieve consensus as thorough and comprehensive discussion of an issue give pleasure of a minority of the respondents $(40.0 \%)$, while the majority $(60.0 \%)$ reaching an agreement regarding a controversial issue. Thus, according to $55.0 \%$ of them think it is worse to be unnecessarily picky and capricious.

The last pair of characteristics of the individual psychological portrait is the alternative "Judging-Perceiving". When you need to make a choice, 56.3 percent of the respondents are very careful and $43.7 \%$ - act suddenly, impulsively. $87.5 \%$ prefer things to be settled and arranged, and $12.5 \%$ - not been solved and still not sorted. Usually prefer to act after thoroughly assessed all possibilities $61.3 \%$ and $38.7 \%$ - just by leaving the case. $81.3 \%$ of those who wish to practice spa and wellness tourism feel more comfortable visiting destination by prior arrangement as $18.7 \%$ feel more comfortable in a new destinationin which are accidentally stumbled. $72.5 \%$ of respondents usually put their trust of organization, order and consistency and $27.5 \%$ - of chance, surprise and unexpectedly. About 68.8 percent prefer to insure that everything is prepared and arranged, and the other 31.2 percent - the events to be allowed to go on his order. Therefore, 60.0 percent of respondents prefer the planned events, and $40.0 \%$ - unplanned. According to the results $63.8 \%$ tend to act more deliberately than impulsively and 36.2 percent - the opposite.

These results allow determining the dominant and the closely related to it psychological portraits that are possible combinations of these features plus any cases in which the same pair is equal in priority to the other. The most dominating psychological portrait is ESFJ (Hugo or Provider - emotional sensitive extravert) for $13.8 \%$ of the sample. After it, with $8.8 \%$ come the portraits ESTJ (Schtirlitz or Supervisor - logical sensitive extravert) and ISTJ (Gorky or Inspector - logical sensitive introvert). These three psychological portraits displayed temperament type "Epimetheus" or "Guardian" (SJ) as leading to the profile of the studied Western European spa and wellness tourists.

\section{Discussion}

Psychologists have long started to pay attention to the significant individual differences in human behavior. Even in ancient times people have noticed that there are some typical "behavior models": in the same situation, a person with certain psychological qualities always behaves in a certain way.

\section{7}

Corresponding author: stoyanovamilena@abv.bg

DOI: 10.1515/asn-2017-0013 
Temperament is one of the most important characteristics of the individual. The interest in it is linked to evidence of mental differences between people - differences in the depth, intensity, stability of emotions, emotional sensitivity, pace, energy operations and other dynamic individually resistant characteristics of mental life, behavior, actions that traditionally belong to a temperament.

Therefore temperament is a combination of stable individual psychological characteristics, determining the dynamics of psychological activity of an individual and leaving relatively constant for different motives, content and objectives of the activity. It is the most active individual peculiarity of personality that in the process of activity can not be substantially altered. Of all the components of the overall mental activity, it is most closely associated with the emotional sphere.

Emotional excitability as a property of temperament is the rhythm of the flow of emotions in different temperaments. The strength of emotions is also a brightly outlined property. Reactivity and activity also characterized temperament. Mental states rigidity, extroversion, introversion are also properties of the temperament. These parameters indicate that the psychological characteristics of temperament are complex. It is a mental quality of personality that determines individual processes, states and properties, ie temperament has the ability to characterize personality in pshychological activity.

Therefore extraversion is targeting interest in the environment objects, ie in extravert state man acts, thoughts, feelings, perceived experiences with respect to the object. A person with such an attitude is willing to respond immediately and directly to an external stimulus. Introversion, respectively, include withdrawal of interest from the object and directing his subjects (as personal conscious experience of people). In introvert state perceptions, thoughts, actions, feelings, experiences are determined by subjective factors. Here the individual reacts with delayed reactions and act on the basis of subjective reasons that follow external stimulation.

Names of the four types of temperament according to Kiersey is, but there is a symbolics of generalized traits of mythological characters. The term "temperament" suggests realization of the characteristics of the individual which give an unique originality of all the individual's manifestations and their personality.

The socionic classification of the temperament types and psychological portraits, gives information about the personal direction of the behavior of spa and wellness tourists who made a choice to satisfy their needs. This study aims to establish the adequacy and productivity of research methodology in western spa and wellness tourists in Bulgaria.

\section{Conclusions}

In conclusion it can be said that socionics can help people understand themselves better, to find their place in society and in the world. Temperament is a configuration of obvious personality traits such as communication habits, ways of action as well as a complex of distinctive attitudes, values and talents. It also includes personal needs, contributions in the workplace and the role they play in society. Every temperament type and every psychological portrait has its own unique qualities and flaws, strenghts and challenges. In order to use the idea of temperament most effectively, it is important to understand that all four types are not simply arbitrary set of features, but the result of the interaction of two basic dimensions of human behavior: our communication and our actions, our words and our acts, or just what we say and what we do.

\section{References}

[1] Alexandrova, N,. N. Boyadzhieva, Kl. Sapundzhieva, Tsh. Kolarova. Sotshionikata v sotshialnata sfera. „Sv. Kliment Ohridski”, Sofia, 2004.

[2] Hawkins, D. I., Best, R. J., \& Coney, K. A. Consumer behavior: Building marketing strategy (9th ed.). Boston: McGraw Hill, 2003.

[3] Petkov, A. Lichnost I psihichna adaptatshiya. "Nauka I izkustvo", Sofia, 1987.

[4] Robert A. Baron \& Donn Byrne. Social Psyhology: Understanding Humanic Interaction. $5^{\text {th }}$ ed. (Boston:

Allyn and Bacon, 1987). In: Solomon, M. Potrebitelskoto povedenie, "Iztok - Zapad", Sofia, 2001.

[5] Snedecor, G and W. Cochran. Statistical Methods, New York, Iowa, 1967.

[6] http://www.keirsey.com/drdavidkeirsey.aspx (available on 5.07.2015). 